\title{
Mouth Mask versus Pursed Lip Breathing on Ventilatory Functions and Dyspnea Index in Chronic Obstructive Pulmonary Disease
}

\author{
SOMA A.G. ABD-ELGHANY, M.Sc.*; NESREEN G. ELNAHAS, Ph.D.*; \\ ZAHRA M.H. SERRY, Ph.D.* and YOUSSEF M.A. SOLIMAN, M.D.** \\ The Department of Physical Therapy for Cardiovascular/Respiratory Disorder and Geriatrics, \\ Faculty of Physical Therapy* and The Department of Chest, Faculty of Medicine**, Cairo University
}

\begin{abstract}
Background: Chronic Obstructive Pulmonary Disease (COPD) is a rising health problem. Dyspnea causes reduction of functional status and quality of life in it. Pursed Lips Breathing (PLB) and mouth mask use to reduce dyspnea and improve quality of life.

Aim of Study: To compare the effect of mouth mask versus pursed lip breathing on ventilatory functions and dyspnea index in patient with chronic obstructive lung disease.

Subjects and Methods: Forty men patient presented with chronic obstructive pulmonary disease $\left(\mathrm{FEV}{ }_{1} / \mathrm{FVC}<0.70\right)$ were selected from outpatient clinic at Chest Department Kasr El-Ainy Hospital, age ranged from 50-65 years old. Ventilatory functions, Dyspnea index, oxygen saturation, CATscore questionnaire, were measured pre and post training program. Patients were assigned in two groups. Group (A): Consisted of 20 patients were treated by expiratory breathing through Mouth Mask plus standard chest physiotherapy. Group (B) consisted of 20 patients were treated by pursed lip breathing plus standard chest physiotherapy Program was for five days per week for 8 weeks.
\end{abstract}

Results: There was a significant increase in FVC, FEV and FEV 1/FVC post-treatment compared with that pretreatment with a percent of improvement $19.25 \%, 44.29 \%$, $21.5 \%$ respectively in the group A and $8.7 \%, 18.37 \%, 8.9 \%$ respectively in group B $(p<0.001)$. There was a significant decrease in CAT post-treatment compared with that pretreatment with apercent of improvement $61.07 \%$ and $46.07 \%$ respectively in the group A and $\mathrm{B}(p<0.001)$.

There was a significant increase in $\mathrm{FEV}_{1}$ with the mean difference between both groups was $0.28 \mathrm{~L}$ and a significant decrease in CAT of the group A compared with that of the group B the mean difference between both groups was -5.1 $(p<0.05)$. There was a significant decrease in DI pre and post 3 min step test post-treatment in the group A and B compared

Correspondence to: Dr. Soma A.G. Abd-Elghany,

The Department of Physical Therapy for Cardiovascular/ Respiratory Disorder and Geriatrics, Faculty of Physical Therapy, Cairo University with that pre-treatment $(p<0.0001)$. Pre-treatment the median value of DI (pre 3 min step test) of the group A was 2 and group B was 2 and that post-treatment was 0 for group A and 1 for group B. Pre-treatment the median value of DI (post 3 min step test) of the group A was 3 and group B was 3 and post-treatment for group A was 1 and group B was 1.5. and comparison between the A and B post-treatment revealed a significant decrease in DI pre and post $3 \mathrm{~min}$ step test of the group A compared with that of the group B.

Conclusion: Mouth mask and pursed lip breathing are effective in improving ventilatory functions, improving of dyspnea, improving of health status and physical activity in patient with chronic obstructive lung disease. As there is improvement in CAT score questionnaire ventilatory parameters and Dyspnea index in COPD.
Key Words: Mouth mask - Pursed lip breathing - Ventilatory functions - Dyspnea index - CAT score-Chronic obstructive pulmonary disease.

\section{Introduction}

CHRONIC obstructive pulmonary disease is a progressive respiratory disease that has a significant impact on the patient's ability to work and the quality of life [1].

Chronic obstructive pulmonary disease is a leading cause of morbidity and mortality worldwide. It is a major burden globally and induces an economic and social burden. According to the Global Burden of Disease study, it caused 3.2 million deaths in 2015, accounting for 5\% of all deaths worldwide, making it the third leading cause of death in the world and it is estimated that about 64 million people in the world will get COPD by $2030[2,3]$

COPD caused approximately 3.2 million deaths worldwide in 2017 and there was a $17.5 \%$ increase 
in the number of deaths between 2007 and 2017 It is due to continued exposure of risk factors especially smoking and aging population [4].

In Egypt, the prevalence of COPD among highrisk Egyptians was $9.6 \%$. By GOLD criteria. A higher prevalence of grade $2(69 \%)$ and grade 3 $(17 \%)$ and lower prevalence of grade $1(3 \%)$ COPD. So increasing awareness of COPD in the general population and specifically among high-risk individuals can aid in the early diagnosis of this disease [5].

COPD is defined as a common, preventable and treatable disease characterized by persistent respiratory symptoms and airflow limitation that is due to airway and/or alveolar abnormalities, usually caused by significant exposure to noxious particles or gases and it was defined spirometrically according GOLD based FEV 1/FVC ratio less than 0.7 and the severity of airflow obstruction is defined through GOLD severity grades based on the ratio of FEV 1 to its predicted value, with GOLD 1,2, 3 and 4 defined around cut-off points of $80 \%, 50 \%$, and $30 \%$ [6,7].

Dyspnea, productive cough, reduced maximum expiratory flow and slow expiratory volume are cardinal features of COPD. Also there is degree of expiratory airflow limitation which defines the severity of COPD. Decline in forced expiratory volume in first second (FEV 1) and airflow limitation provides a useful description of the severity of the pathological changes in COPD and are essential in the diagnosis of COPD [8].

Dyspnea is the most common and debilitating symptom in COPD and it is the primary symptom that limits physical activity in more advanced disease. It is a core feature of panic attacks in COPD patient fear of dyspnea may lead to avoidance of physical activity, deconditioning, reduction in functional status, reduction in quality of life and disability and anxiety in COPD [9].

Pursed Lip Breathing (PLB) is an excellent technique that decrease dyspnea in COPD, increase the tolerance of activities, increase oxygen saturation and improve ventilation and gas exchange. These improvements observed from an increase in minutes of ventilation, tidal volume increases, and optimization of functional lung capacity. It simply imposes a slight obstruction to expiratory air flow at the mouth which generates back pressure throughout the airway causing stenting effect which helps the airways opened and assists exhalation and thereby, better lung emptying it was reported that pursed lip breathing showed [10].
Mouth Mask was used recently instead of mouth taping that hold the aperture of mouth as of pursed lip breathing, giving continuous feedback to the patient and decrease perioral muscle fatigue. Both taping and mask work on the same principle as pursed lip breathing, help in maintaining the sustained effect of PLB, add more uniform resistance to the expiratory flow, prolong the breathing cycle, avoid the perioral muscle fatigue, give a continuous feedback, and easier to administer. It can be used as an alternative for PLB, especially when patients find it difficulty in pursing their lips voluntarily to exhale effectively or even when PLB is required for a prolonged duration [11].

Mouth mask used instead of mouth taping because application of mouth taping regularly can be very difficult for the patient and removal of the tape can be painful for the patient due to its adhesive effects, so a mouth mask was designed. It has a improvement in dyspnea and functional capacity in patients who received breathing through it [12]

The purpose of the study was to compare the effect of mouth mask versus pursed lip breathing on ventilatory functions and dyspnea index in patient with chronic obstructive lung disease. As there is little researches about the mouth mask and how much it effects on ventilatory functions and dyspnea in COPD patients.

\section{Subjects and Methods}

Forty men COPD patients included in the study aged from 50-65 years old. They were recruited from outpatient chest clinic at Kaser El-Ainy Hospital, from April 2019 to October 2019. Patients randomly assigned into 2 groups (Group $\mathrm{A}$ and Group B) equal in number. They were diagnosed by chest physician based on history, physical examination, smokers more than 15 years, chest Xray and that post bronchodilator ratio of FEV ${ }_{1} / \mathrm{FVC}$ is less than 0.7 to diagnose COPD according to (GOLD) guidelines and with BMI less than 30 $\mathrm{kg} / \mathrm{m}^{2}$. All patients are free from recent eye surgery, hernia, any significant musculoskeletal disorders and progressive neuromuscular disorders did not have psychiatric disorders and malignant disease.

Patients were assigned in two groups. Group (A): Consisted of 20 patients were treated by expiratory breathing through Mouth Mask plus standard chest physiotherapy (this mask was designed in a way that only only $1 / 4$ th of the total lip length is kept open) group (B) consisted of 20 patients were treated by pursed lip breathing plus 
standard chest physiotherapy program was for five days per week for 8 weeks.

Ethical consideration: Purposes of the study, methodology and experiments protocol were explained to every patient participated in the study and they agreed to share in this study.

Ethical committee: Ethical approved from Scientific Researches Ethical Committee of Faculty of Physical Therapy, Cairo University. NO.P.T. REC/012/002237.

\section{II- Measures and equipment:}

\section{Evaluating equipment:}

1- Measurement of pulmonary function tests by spirometer to asses pulmonary function tests (FVC, FEV 1/FVC, FEV 1) (Jaeger Vyntus IOS spirometer was used) pre and post intervention.

2-Measurement of the sensation of breathlessness (dyspnea) by: Dyspnea index (fifteen count breathlessness score): The patient was asked to take deep initial breathe and count from 1 to 15 within about 8 second and the therapist counted how many breathes that the patient took in between to complete the counting [13]. This index was performed when the patient was at rest and immediately after 3 minute step test.

3- The 3-min step test: The patient was asked to step up and down single step which was $20 \mathrm{~cm}$ high $22 \mathrm{~cm}$ in depth. The stepping rate was between 14 and 16 step per min for 3 min [14]

4- Assessment of health status in COPD patient by: COPD Assessment Test Questionnaire. CAT Questionnaire consists of 8 questions and scores of each question range from 0 to 5 , total scores range from 0 to 40 [15]. The more higher the score, the more severity of the disease. The score was recorded pre intervention and post inter intervention and changes in score was calculated by statistical analysis.

\section{Therapeutic equipment:}

Mouth mask: The mask was designed in a way that only central aperture, (only $1 / 4$ th of the total lip length is kept open). All patients who received mouth mask were asked to wear the mask and demonstrate the breathing pattern, Inhale from nose and exhale from mouth [12].

\section{Treatment procedures:}

1- Group A (Moth mask): The patient assumed comfortable position, asked to wear mask and inhale slowly through his nose for two counts, then patient held the breath for account of three, finally the patient was asked to exhale slowly and gently not do forceful exhalation through mask.

2- Group B (pursed lip breathing): The patient assumed comfortable position and asked to relax his neck and shoulder muscles. Then inhale slowly through his nose for two counts, while keeping mouth closed. The patient held the breath for account of three and informed to pucker or purse his lips as if trying to whistle or gently flicker the flame of a candle. Then exhale slowly and gently through the pursed lip while counting to four.

IN both groups the patient started with quite breathing for 3 repetitions take rest for 5 seconds, then performed diaphragmatic breathing for 3 repetitions, took rest for 10 seconds and finally performed pursed lip breathing for 8 repetitions (with 5 second rest between each 4 repetitions of PLB). At first week the patient did 3-4 sets per session with one minute rest between each set, number of sets increased gradually till reached 5 sets at the last week [16].

\section{Statistical analysis:}

Descriptive statistics and unpaired $t$-test were conducted for comparison of subject characteristics between both groups. Normal distribution of data was checked using the Shapiro-Wilk test for all variables. Levene's test for homogeneity of variances was conducted to test the homogeneity between groups. Unpaired $t$-test was conducted to compare the mean values of FEV 1, FVC, FEV 1/ FVC and CAT between the group A and B. Paired $t$-test was conducted for comparison between pre and post-treatment in each group. DI grades were compared between groups by Mann-Whitney U test and between pre and post-treatment in each group by Wilcoxon Signed Ranks the level of significance for all statistical tests was set at $p<0.05$. All statistical analysis was conducted through the Statistical Package for Social Studies (SPSS) version 25 for windows (IBM SPSS, Chicago, IL, USA).

\section{Results}

\section{Subject characteristics:}

Table (1) showed the subject characteristics of the group A and B. There was no significant difference between both groups in the mean age, weight, height and BMI $(p>0.05)$. 
Table (1): Comparison of subject characteristics between group $\mathrm{A}$ and $\mathrm{B}$.

\begin{tabular}{lccccc}
\hline & $\begin{array}{c}\text { Group A } \\
\mathrm{X} \pm \mathrm{SD}\end{array}$ & $\begin{array}{c}\text { Group B } \\
\mathrm{X} \pm \mathrm{SD}\end{array}$ & MD & $\begin{array}{c}t- \\
\text { value }\end{array}$ & $\begin{array}{c}p \text { - } \\
\text { value }\end{array}$ \\
\hline Age (years) & $59.4 \pm 1.98$ & $58.8 \pm 3.34$ & 0.6 & 0.68 & 0.49 \\
Weight $(\mathrm{kg})$ & $69.75 \pm 10.46$ & $71.7 \pm 11.7$ & -1.95 & -0.55 & 0.58 \\
Height $(\mathrm{cm})$ & $171.1 \pm 5.45$ & $172.3 \pm 3.9$ & -1.2 & -0.8 & 0.42 \\
$\mathrm{BMI}\left(\mathrm{kg} / \mathrm{m}^{2}\right)$ & $23.73 \pm 2.6$ & $24.06 \pm 3.1$ & -0.33 & -0.36 & 0.71 \\
\hline $\mathrm{X} \quad:$ Mean. & & & & \\
SD : Standard Deviation. & & & & \\
$p$-value : Probability value. & & & & &
\end{tabular}

Effect of treatment on $F E V_{1}, F V C, F E V_{1} / F V C$, CAT and DI:

- Within group comparison:

There was a significant increase in $\mathrm{FEV}_{1}, \mathrm{FVC}$ and $\mathrm{FEV}_{1} / \mathrm{FVC}$ post-treatment compared with that pre-treatment in the group A and B $(p<0.001)$. There was a significant decrease in CAT posttreatment compared with that pre-treatment in the group A and B ( $p<0.001)$ (Table 2), Figs. $(1,2,3)$.

Table (2): Mean FEV 1, FVC, FEV $1 /$ FVC and CAT pre and post-treatment of the group $\mathrm{A}$ and $\mathrm{B}$.

\begin{tabular}{|c|c|c|c|c|c|}
\hline & $\begin{array}{l}\text { Group A } \\
\mathrm{X} \pm \mathrm{SD}\end{array}$ & $\begin{array}{l}\text { Group B } \\
\mathrm{X} \pm \mathrm{SD}\end{array}$ & MD & $\begin{array}{c}t- \\
\text { value }\end{array}$ & $\begin{array}{c}p- \\
\text { value }\end{array}$ \\
\hline \multicolumn{6}{|l|}{ FEV1 (L): } \\
\hline Pre-treatment & $1.4 \pm 0.37$ & $1.47 \pm 0.34$ & -0.07 & -0.59 & 0.55 \\
\hline Post-treatment & $2.02 \pm 0.4$ & $1.74 \pm 0.44$ & 0.28 & 2.15 & $0.03 *$ \\
\hline MD & -0.62 & -0.27 & & & \\
\hline$\%$ of change & $44.29 \%$ & $18.37 \%$ & & & \\
\hline$t$-value & $\begin{array}{l}-18.84 \\
p=0.0001\end{array}$ & $\begin{array}{l}-3.94 \\
p=0.001 *\end{array}$ & & & \\
\hline \multicolumn{6}{|l|}{$F V C(L):$} \\
\hline Pre-treatment & $2.65 \pm 0.42$ & $2.76 \pm 0.51$ & -0.11 & -0.79 & 0.43 \\
\hline Post-treatment & $3.16 \pm 0.47$ & $3 \pm 0.51$ & 0.16 & 1.08 & 0.28 \\
\hline MD & -0.51 & -0.24 & & & \\
\hline$\%$ of change & $19.25 \%$ & $8.7 \%$ & & & \\
\hline$t$-value & $\begin{array}{l}-9.02 \\
p=0.0001 *\end{array}$ & $\begin{array}{l}-9.35 \\
p=0.0001 *\end{array}$ & & & \\
\hline \multicolumn{6}{|l|}{ FEV $1 / F V C(\%):$} \\
\hline Pre-treatment & $52.81 \pm 9.72$ & $53.7 \pm 10.14$ & -0.89 & -0.28 & 0.78 \\
\hline Post-treatment & $64.16 \pm 9.3$ & $58.48 \pm 12.57$ & 5.68 & 1.62 & 0.11 \\
\hline MD & -11.35 & -4.78 & & & \\
\hline$\%$ of change & $21.5 \%$ & $8.9 \%$ & & & \\
\hline$t$-value & $\begin{array}{l}-6.67 \\
p=0.0001 *\end{array}$ & $\begin{array}{l}-2.25 \\
p=0.03 *\end{array}$ & & & \\
\hline \multicolumn{6}{|l|}{ CAT: } \\
\hline Pre-treatment & $32.75 \pm 4.35$ & $33.1 \pm 3.09$ & -0.35 & -0.29 & 0.77 \\
\hline Post-treatment & $12.75 \pm 4.08$ & $17.85 \pm 6.1$ & -5.1 & -3.1 & $0.004 *$ \\
\hline MD & 20 & 15.25 & & & \\
\hline$\%$ of change & $61.07 \%$ & $46.07 \%$ & & & \\
\hline$t$-value & $\begin{array}{l}17.16 \\
p=0.0001 *\end{array}$ & $\begin{array}{l}12.99 \\
p=0.0001 *\end{array}$ & & & \\
\hline
\end{tabular}

X : Mean.

SD : Standard Deviation.

MD : Mean Difference.

$p$-value : Probability value. : Significant.

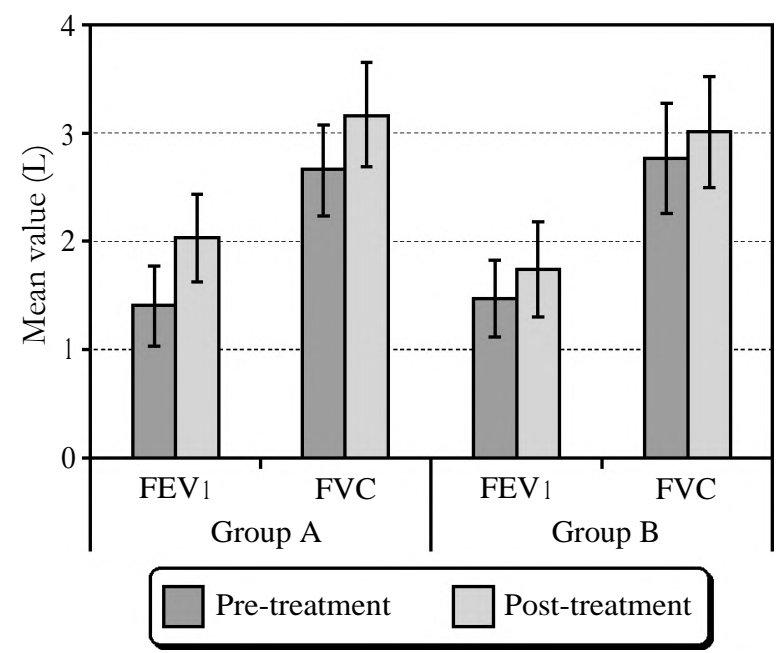

Fig. (1): Mean FEV 1 and FVC pre and post-treatment of the group $\mathrm{A}$ and $\mathrm{B}$.

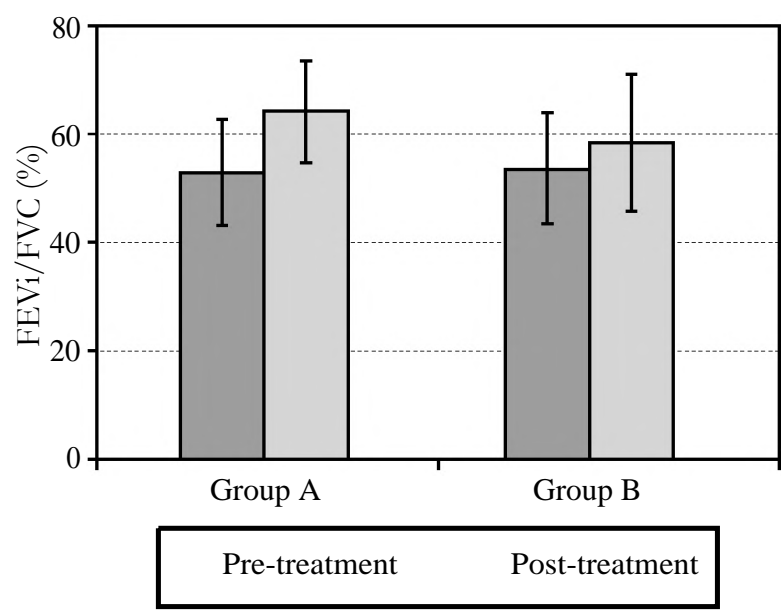

Fig. (2): Mean FEV ${ }_{1} / \mathrm{FVC}$ pre and post-treatment of the group $\mathrm{A}$ and $\mathrm{B}$.

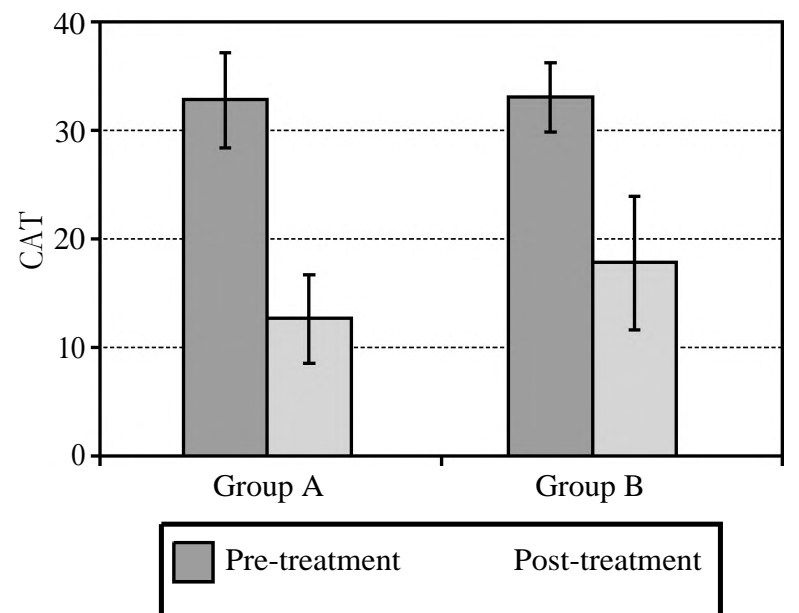

Fig. (3): Mean CAT pre and post-treatment of the group A and $\mathrm{B}$.

There was a significant decrease in DI pre and post 3 min step test post-treatment in the group A and B compared with that pre-treatment $(p<0.0001)$ (Table 3), Fig. (4). 


\section{- Between groups comparison:}

There was no significant difference in $\mathrm{FEV}_{1}$, FVC, FEV ${ }_{1} / \mathrm{FVC}$ and CAT between both groups pre-treatment $(p>0.05)$. Comparison between both groups post-treatment revealed a significant increase in $\mathrm{FEV}_{1}$ and a significant decrease in CAT of the group A compared with that of the group B $(p<0.05)$ (Table 2), Figs. $(1,2,3)$.

There was no significant difference in DI pre and post $3 \mathrm{~min}$ step test between both groups pretreatment $(p>0.05)$. Comparison between the A and B post-treatment revealed a significant decrease in DI pre and post $3 \mathrm{~min}$ step test of the group A compared with that of the group B $(p<0.01)$ (Table 3), Fig. (4).

Table (3): Median values of DI pre and post-treatment of group $\mathrm{A}$ and $\mathrm{B}$.

\begin{tabular}{|c|c|c|c|c|}
\hline DI & $\begin{array}{l}\text { Group A } \\
\text { Median }\end{array}$ & $\begin{array}{l}\text { Group B } \\
\text { Median }\end{array}$ & $\begin{array}{c}\text { U- } \\
\text { value }\end{array}$ & $\begin{array}{c}p- \\
\text { value }\end{array}$ \\
\hline \multicolumn{5}{|c|}{ DI pre 3 min step test: } \\
\hline Pre-treatment & 2 & 2 & 200 & 1 \\
\hline Post-treatment & 0 & 1 & 123 & $0.01 *$ \\
\hline \multirow{2}{*}{ Z-value } & -4.17 & -3.87 & & \\
\hline & $p=0.0001^{* *}$ & $p=0.0001 *$ & & \\
\hline \multicolumn{5}{|c|}{ DI post 3 min step test: } \\
\hline Pre-treatment & 3 & 3 & 190 & 0.75 \\
\hline Post-treatment & 1 & 1.5 & 74.5 & $0.0001 *$ \\
\hline \multirow[t]{2}{*}{ Z-value } & -4.06 & -3.75 & & \\
\hline & $p=0.0001 * *$ & $p=0.0001$ & & \\
\hline
\end{tabular}

U-value : Mann-Whitney test value.

Z-value : Wilcoxon signed ranks test value.

$p$-value : Level of significance.

Significant.

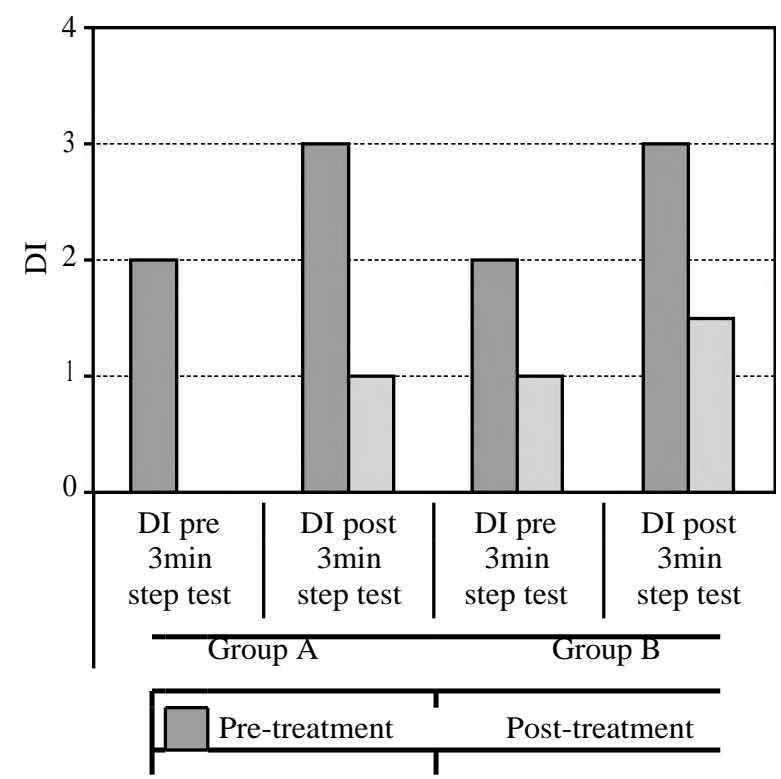

Fig. (4): Mean DI pre and post-treatment of the group A and B.

\section{Discussion}

The present study conducted to evaluate the effectiveness of mouth mask versus pursed lip breathing on ventilatory functions and dyspnea index in COPD patients. Forty men COPD patients were enrolled in this study with their age ranged from 50 to 65 years old. Participants assigned into 2 groups, 20 patients in group A and 20 patient in group B.

The current study reflected that improvement of the ventilatory function tests included measurements of forced vital capacity (FVC), forced expiratory volume in one second (FEV 1), ratio of forced expiratory volume in one second to forced vital capacity $\left(\mathrm{FEV}_{1} / \mathrm{FVC}\right)$, improvement of dyspnea index at rest and after $3 \mathrm{~min}$ step test (exertional dyspnea), and improvement in COPD assessment test questionnaire score (CAT) in both groups (A $\&$ B), but mouth mask group (A) was better than group (B).

Regarding the effect of pursed lip breathing on ventilatory functions, the current work demonstrated that has caused a significant improvement in ventilatory function as forced vital capacity (FVC) which showed a significant increase with a percentage of change $8.7 \%$, forced expiratory volume in one second $\left(\mathrm{FEV}_{1}\right)$ showed statistical significant increase with percentage of change $18.37 \%$, $\mathrm{FEV}_{1} / \mathrm{FVC}$ showed statistical significant increase with a percentage of change $8.9 \%$. This result comes in agreement with the study done by SADE et al., [17] who found that breathing strategies including pursed lip breathing, diaphragmatic breathing has a significant increase in FEV and $\mathrm{FEV}_{1} / \mathrm{FVC}$ values, when compared with control group.

To our knowledge few studies addressed the effect of mouth mask on ventilatory functions, dyspnea and CAT in COPD. Our study showed a significant increase in ventilatory parameters $\left(\mathrm{FEV}_{1}\right.$ FVC, FEV 1/FVC), CAT and dyspnea index more than PLB, this expressed in improvement in health status, physical activity and confidence of the COPD patient because dyspnea improved and became better than before intervention. On one side the result of these study was supported by the study done by with Sachdeva et al., [12] that proved that pursed lip breathing through Mouth Mask showed significantly higher improvement in relieving dyspnea and in increasing the functional capacity. When performed 5 days per week for $(5$ days in a week, 2 times per day for 20 minutes per session). 
A possible explanation for that mouth Mask has a higher improvement in dyspnea and functional capacity than pursed lip breathing, was attributed to that mouth mask was used as an alternative mouth taping because application of mouth taping regularly can be very difficult for the patient and removal of the tape can be painful for the patient due to its adhesive effects. So a mouth mask was designed [12]. A possible explanation for the increase was attributed to The mask works on the same principle as PLB helped to hold the aperture of the mouth as of PLB and gave the continuous feedback to the patients. So, it helped to reduce dyspnea by reversing dynamic hyperinflation through increased intraluminal pressure in the airways resulting in a shift of equal pressure point from distal to proximal and helped in preventing airway collapse.

On the other side the result of these study opposes to the study conducted by Maind et al., [18] who proved that Moth Taping and PLB both were equally effective in improving the response to exercise in terms of increased treadmill walking time and post-test dyspnea status and recovery of vital parameters, without any significant differences between the two techniques.

The COPD Assessment Test (CAT) questionnaire is a short, easy to-complete tool, is likely to be relevant alternative to complex tool as the St. George's Respiratory Questionnaire (SGRQ) as CAT not time consuming that has been developed to help patients and clinicians to assess the health status and assessing the symptoms in COPD and enable better communication between patients and physicians about these consequences of their disease on life. It has a broader coverage of the impact of COPD on the patient's daily life and well-being [19].

This study demonstrate that both PLB and mouth mask has positive effect on the CAT score, as improvement in the CAT represent improvement in health status, physical ability, confidence and symptoms in COPD patients. The more decline in the score, the more improvement of the patient. Percent of improvement in mouth mask and PLB is $61.07 \%$ and $46.07 \%$ respectively.

This result comes in agreement with the study conducted by Smid et al., [20]. Who demonstrated that pulmonary rehabilitation for 8 weeks, 5 session per week showed that CAT are responsive to pulmonary rehabilitation in patients with moderate to very severe COPD.
Mouth mask has a high significant improvement in CAT score and $\mathrm{FEV}_{1}$ and this in agreement with randomized controlled trial conducted by Lin et al., [21] demonstrated that in patients with severe COPD, breathing against Positive End Expiratory Pressure (PEEPi) was modestly beneficial in terms of the CAT score and health status. A breathing exercise program strategy employing an appropriate PEEP may improve their pulmonary functional capacity, exercise tolerance and health-related quality of life. The effects of the treatments on the COPD assessment test (CAT) score, there were statistically significant differences in the, CAT scores and $\mathrm{FEV}_{1} \%$ pred values between the baseline and month $18(p<0.0001)$ in the intervention group.

As there was little researches about the effect of mouth mask in COPD patients, so this study investigated the effect of mouth mask on dyspnea and ventilatory function and there was higher improvement that may be attributed to first, the mask has a psychological motivation and giving feedback for patient. Second, patient perform exercise regular as the mask easy to use and to maintain positive pressure for long time without any fatigue in perioral muscles. Third, difference in diameter of lip opening in PLB according to perception and performance of each patient in contrast to the mask that has a constant diameter mask the effect of the mask higher than PLB. So according this result mouth mask is recommended to use in pulmonary rehabilitation as an alternative to PLB.

\section{Conclusion:}

Mouth mask and pursed lip breathing are effective in improving ventilatory functions, improving of dyspnea, improving of health status and physical activity in patient with chronic obstructive lung disease. Als there is improvement in CAT score questionnaire ventilatory parameters and Dyspnea index in COPD.

\section{References}

1- PAVORD I.D., JONES P.W., BURGEL P.R. and RABE K.F.: Exacerbations of COPD. International journal of chronic obstructive pulmonary disease, 11 (Spec Iss), 21, 2016.

2- SORIANO J.B., ABAJOBIR A.A., ABATE K.H., ABERA S.F., AGRAWAL A., AHMED M.B. and ALAM N.: Global, regional, and national deaths, prevalence, disability-adjusted life years, and years lived with disability for chronic obstructive pulmonary disease and asthma, 19902015: A systematic analysis for the Global Burden of Disease Study 2015. The Lancet Respiratory Medicine, 5 (9): 691-706, 2017.

3- De OCA M.M. and PADILLA J.R.P.: Global Initiative for Chronic Obstructive Lung Disease (GOLD)-2017: La visión desde alat. Archivos de bronconeumología: 
Organo oficial de la Sociedad Española de Neumologíay Cirugía Torácica SEPAR y la Asociación Latinoamericana de Tórax (ALAT), 53 (3): 87-8, 2017.

4- HALPIN D.M., CELLI B.R., CRINER G.J., FRITH P., VARELA M.V.L., SALVI S. and AISANOV Z.: It is time for the world to take COPD seriously: A statement from the GOLD board of directors. European Respiratory Journal, 54: 1900914?, 2019.

5- SAID A.F., EWIS A.A., OMRAN A.A., MAGDY M.E. and SALEEB M.F.: Prevalence and predictors of chronic obstructive pulmonary disease among high-risk Egyptians. Egyptian Journal of Bronchology, 9 (1): 27, 2015.

6- VOGELMEIER C.F., CRINER G.J., MARTINEZ F.J., ANZUETO A., BARNES P.J., BOURBEAU J. and FRITH P.: Global strategy for the diagnosis, management, and prevention of chronic obstructive lung disease 2017 report. GOLD executive summary. American journal of respiratory and critical care medicine, 195 (5): 557-82, 2017.

7- MIRZA S., CLAY R.D., KOSLOW M.A. and SCANLON P.D.: (2018, October). COPD guidelines: A review of the 2018 GOLD report. In Mayo Clinic Proceedings (Vol. 93, No. 10, pp. 1488-502). Elsevier, 2018.

8- ARTICLE R., NEHAL S., MANISHA S., HOSPITAL B.M., HOSPITAL B.M., BYE R. and CHOWK N.K.: International Journal of Health Sciences and Research, 5 (September), 529-40, 2015.

9- MIRAVITLLES M., WORTH H., SOLER CATALUÑA J., PRICE D., De BENEDETTO F., ROCHE N. and RIBERA A.: Observational study to characterise 24-hour COPD symptoms and their relationship with patientreported outcomes: Results from the ASSESS study. Respiratory Research, 15 (1): 122, 2014.

10- HARIYONO R., SANTOSO S.D.R.P., ARSA P.S.A. and ROZI F.: (2017, April). The Influence of Pursed Lip Breathing on Dyspnea, Oxygen Saturation and Activity Tolerance on COPD Patient: Systematic Review. In 8 th International Nursing Conference on Education, Practice and Research Development in Nursing (INC 2017). Atlantis Press, 2017.

11- MAIND G., NAGARWALA R., RETHAREKAR S., GONDANE S., BEDEKAR N., SHYAM A. and SANCHETI P.: Comparison between effect of pursed lip breathing and mouth taping on dyspnoea: A cross sectional study. International Journal of Current Research and Review, 7 (16): 17, 2015.

12- SACHDEVA S., PAWARIA S. and KALRA S.: Effectiveness of Pursed Lip Breathing Versus Mouth Mask on Dyspnea and Functional Capacity in Acute Exacerbation of Chronic Obstructive Pulmonary Disease. International Journal of Health Sciences \& Research, 94 (8): 9, 2018.

13- STEINHORN D.M.: Pulmonary Symptom Management in Adults and Children With Oncologic Disease. Handbook of Supportive Oncology and Palliative Care: WholePerson and Value-based Care, 85, 2018.

14- BOREL B., WILKINSON-MAITLAND C.A., HAMILTON A., BOURBEAU J., PERRAULT H., JENSEN D. and MALTAIS F.: Three-minute constant rate step test for detecting exertional dyspnea relief after bronchodilation in COPD. International journal of chronic obstructive pulmonary disease, 11, 2991, 2016.

15- PÓS-GRADUAÇÃO P. De: Is the COPD Assessment Test sensitive for differentiating COPD patients from active smokers and nonsmokers without lung function impairment ? A population-based study, 44 (3): 213-9, 2018.

16- EALIAS J. and BABU B.: Effectiveness of Pursed Lip Breathing Exercise on Selected Physiological Parameters among COPD Patients. International Journal of Science and Research, 5 (5): 19-22, 2016.

17- SADEI, S IRINTAS E.,INANIR M., ÇEKMECE Ç. and BASYIG IT I: Efficacy of Pulmonary Exercises in Chronic Obstructive Pulmonary Disease. Kocaeli Üniversitesi Saglık Bilimleri Dergisi, 6 (1): 39-44, 2020.

18- MAIND G., NAGARWALA R., RETHAREKAR S., GONDANE S., BEDEKAR N., SHYAM A. and SANCHETI P.: Comparison between effect of pursed lip breathing and mouth taping on dyspnoea: A cross sectional study. International Journal of Current Research and Review, 7 (16), 17, 2015.

19-CASANOVA C., MARIN J.M., MARTINEZ-GONZALEZ C., De LUCAS-RAMOS P., MIR-VILADRICH I., COSIO B. and CALLE-RUBIO M.: Differential effect of modified medical research council dyspnea, COPD assessment test, and clinical COPD questionnaire for symptoms evaluation within the new GOLD staging and mortality in COPD. Chest, 148 (1): 159-68, 2015.

20- SMID D.E., FRANSSEN F.M., HOUBEN-WILKE S., VANFLETEREN L.E., JANSSEN D.J., WOUTERS E.F. and SPRUIT M.A.: Responsiveness and MCID estimates for CAT, CCQ, and HADS in patients with COPD undergoing pulmonary rehabilitation: A prospective analysis. Journal of the American Medical Directors Association, 18 (1): 53-8, 2017.

21- LIN Q., ZHUO L., WU Z., LI C., ZHOU M. and CAI C.: Effects of breathing exercises using home-based positive pressure in the expiratory phase in patients with COPD. Postgraduate Medical Journal, 95 (1127): 476-81, 2019. 


\section{التثفس بقناع الفم مقابل الشفاه المضمومه على وظائف التهوية ومؤشر ضيق التنفس في مرضى الإنسلداد الرئوى المزمن الفئن}

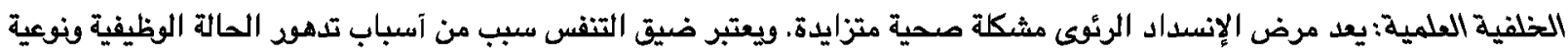

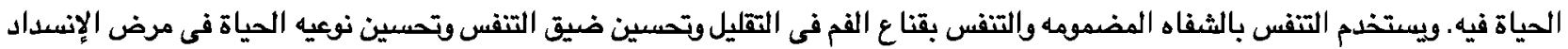
الرئوى المزمن.

الهدف: كان الهدف من هذه الدراسة هو دراسة ومقارنة تآثير التنفس بقناع الفم مقابل الشفاه المضمومه على وظائف التهوية ومؤشر ضيق التنفس فى مرض الإنسداد الرئوى المزمن.

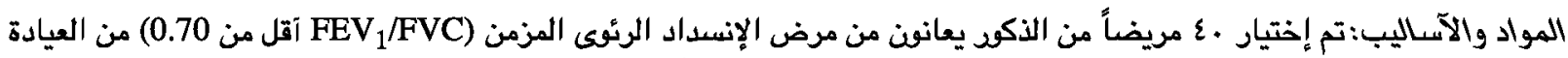

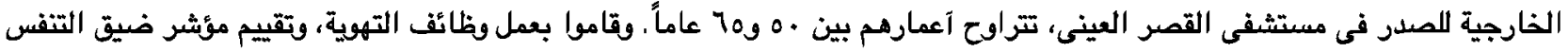

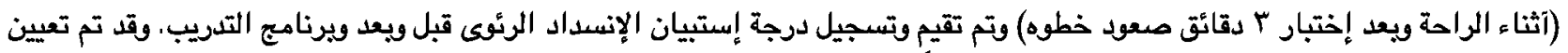

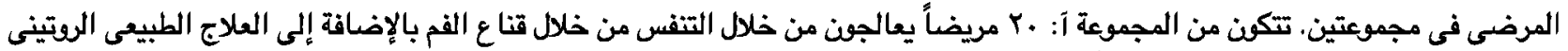

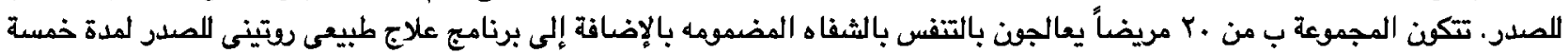
آيام فى الإسبوع لمدة ^ آسابيع.

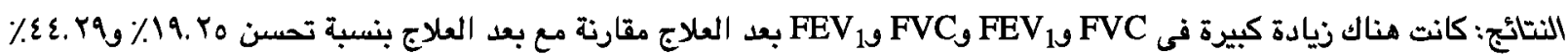

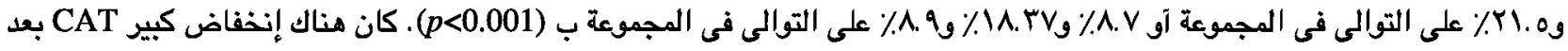

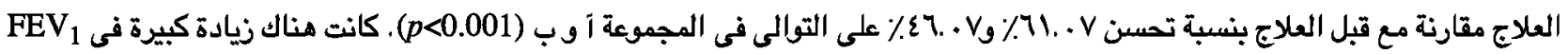

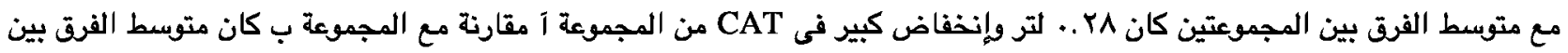

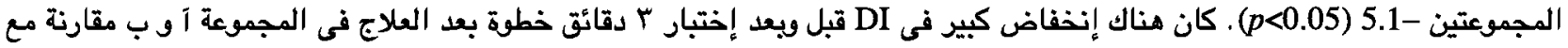

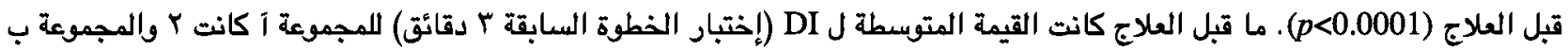

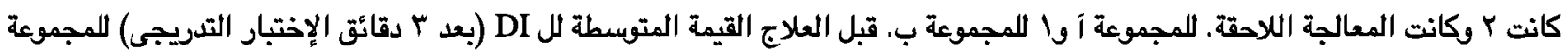

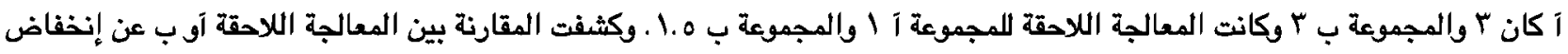

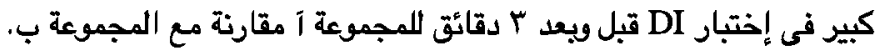

الحخلاصة: التنفس عن طريق قناع الفم والتنفس بالشفاه المضمونه لهم دود فى تحسين وظائف التهوية، وتحسين ضيق التهائ التنفس، وتحسين

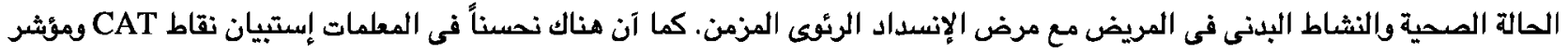
ضيق التنفس فى مرض الإنسداد الرئنى المزئن. 